\title{
Characterization of habitat requirements of European fishing spiders
}

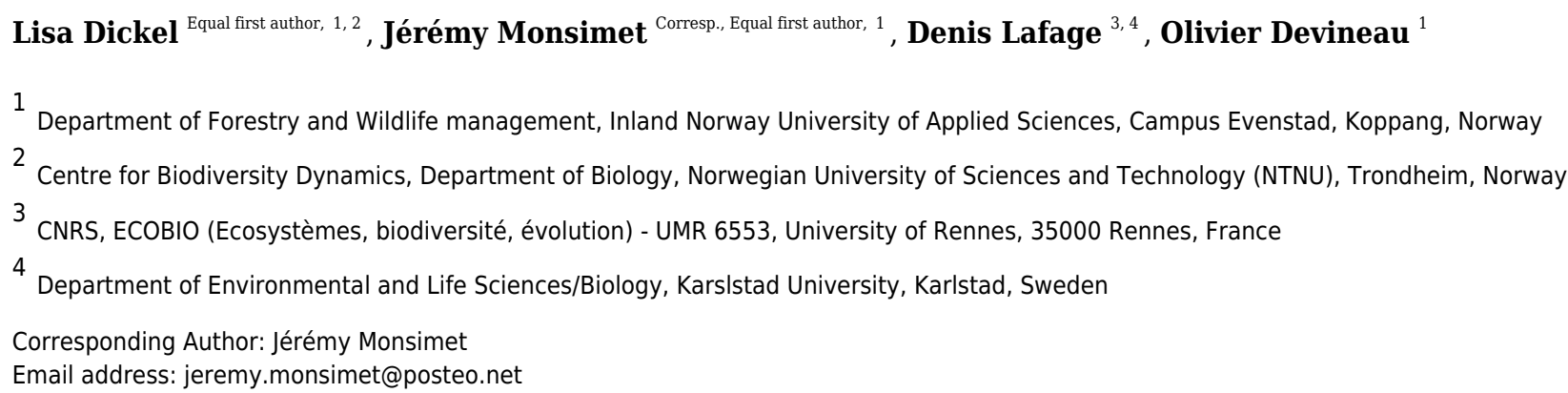

Wetlands are among the most threatened habitats in the world, and so are their species, which suffer habitat loss due to climate and land use changes. Freshwater species, and especially arthropods, receive comparatively little attention in conservation plans, and the goals to stop and reverse the destruction of wetlands published 25 years ago in a manifesto by the Union of Concerned Scientists have not been reached. In this study, we investigated the occurrence and habitat requirements at two spatial scales of two species of European fishing spiders Dolomedes, which rely heavily on declining wetland habitats in Sweden and southern Norway. We collected occurrence data for Dolomedes plantarius and Dolomedes fimbriatus, using a live-determination method. We modelled the placement of nursery webs to describe fine-scale habitat requirements related to vegetation and microclimate. Using a machine learning approach, we described the habitat features for each species and for co-occurrence sites, thus providing insight into variables relevant for the presence and detectability of Dolomedes. Nursery placement is mostly dependent on proximity to water, presence of Carex sp. (Sedges) and crossing vegetation structures, and on humidity, while detection can be affected by weather conditions. Furthermore, cooccurrence sites were more similar to $D$. plantarius sites than to $D$. fimbriatus sites, whereby surrounding forest, water type and velocity, elevation and latitude were of importance for explaining which species of Dolomedes was present. Overall, habitat requirements were narrower for $D$. plantarius compared to $D$. fimbiratus. 


\section{Characterization of habitat requirements of European} 2 fishing spiders

3

4 Lisa Dickel ${ }^{1,2^{*}}$, Jérémy Monsimet ${ }^{2 *}$, Denis Lafage ${ }^{3,4}$, Olivier Devineau $^{2}$

5

$6 \quad{ }^{1}$ Centre for Biodiversity Dynamics, Department of Biology, Norwegian University of Sciences

7 and Technology (NTNU), Trondheim, Norway

$8 \quad 2$ Department of Forestry and Wildlife management, Inland Norway University of Applied

9 Sciences, Campus Evenstad, Koppang, Norway

$10{ }^{3}$ CNRS, ECOBIO (Ecosystèmes, biodiversité, évolution) - UMR 6553, University of Rennes, F 1135000 Rennes, France

$12{ }^{4}$ Department of Environmental and Life Sciences/Biology, Karlstad University, Karlstad,

13 Sweden

14

$15 *$ Shared first-authorship

16 Corresponding Author:

17 Jérémy Monsimet ${ }^{2}$

18 Email address: jeremy.monsimet@posteo.net 
19 Abstract

20 Wetlands are among the most threatened habitats in the world, and so are their species, which

21 suffer habitat loss due to climate and land use changes. Freshwater species, and especially

22 arthropods, receive comparatively little attention in conservation plans, and the goals to stop and

23 reverse the destruction of wetlands published 25 years ago in a manifesto by the Union of

24 Concerned Scientists have not been reached. In this study, we investigated the occurrence and

25 habitat requirements at two spatial scales of two species of European fishing spiders Dolomedes,

26 which rely heavily on declining wetland habitats in Sweden and southern Norway. We collected

27 occurrence data for Dolomedes plantarius and Dolomedes fimbriatus, using a live-determination

28 method. We modelled the placement of nursery webs to describe fine-scale habitat requirements

29 related to vegetation and micro-climate. Using a machine learning approach, we described the

30 habitat features for each species and for co-occurrence sites, thus providing insight into variables

31 relevant for the presence and detectability of Dolomedes. Nursery placement is mostly dependent

32 on proximity to water, presence of Carex sp. (Sedges) and crossing vegetation structures, and on

33 humidity, while detection can be affected by weather conditions. Furthermore, co-occurrence

34 sites were more similar to D. plantarius sites than to D. fimbriatus sites, whereby surrounding

35 forest, water type and velocity, elevation and latitude were of importance for explaining which

36 species of Dolomedes was present. Overall, habitat requirements were narrower for D. plantarius 37 compared to $D$. fimbiratus.

\section{Introduction}

40 Biodiversity is threatened by anthropogenic land use and climate change (Sala et al., 2000).

41 Wetland habitats and species are declining rapidly (Hu et al., 2017), despite being crucial

42 ecosystems for climate change mitigation and even human existence (De Groot et al., 2006).

43 Indeed, they provide habitat for many species and are key for flood regulation and nutrient

44 retention (De Groot et al., 2006). The Ramsar Convention (Ramsar, 2013) and the world's

45 scientists warning to humanity (Kendall, 1992) formulated wetland conservation as a global goal.

46 However, according to Finlayson et al. (2019), not only were wetland protection and restoration

47 goals not reached, but wetlands destruction and loss have proceeded. Conservation priorities are

48 mostly determined through variable and dynamic human values (Lindenmayer \& Hunter, 2010),

49 which has led to unequal conservation efforts across habitats and taxa, with groups like

50 invertebrates (Clark \& May, 2002; Finlayson et al., 2019) and freshwater/wetland species being

51 particularly neglected (Darwall et al., 2011). In addition, according to a review by Kellner \&

52 Swihart (2014), few studies accounted for imperfect detectability, even less so for invertebrate

53 studies than for other taxa, which possibly affects the available knowledge about the actual status

54 of populations and species. 
Although it was recognized almost 20 years ago that there is taxonomic bias in research against arthropods (Clark \& May, 2002), basic knowledge is still missing to inform the conservation of wetland invertebrates. This knowledge is lacking for the two European fishing spiders, namely Dolomedes fimbriatus and Dolomedes plantarius. Both species are semi-aquatic, forage on land as well as on water, and build their nursery webs close to or in vegetation above the water surface (Gorb \& Barth, 1994; Duffey, 2012). The detection of both species is difficult due to their lifestyle, which includes fleeing behavior on and under the water surface when disturbed (Gorb \& Barth, 1994). Dolomedes do not construct webs to capture prey, which makes individuals even more difficult to detect. But like other members of the Pisauridae family, Dolomedes build nursery webs (Stratton, Suter \& Miller, 2004), which are a convenient sign of presence during the reproductive season, thus facilitating their detection. Females are found close to their nursery webs, which is useful for identification, mainly because only adults can be identified with certainty by inspecting their genitals (Roberts, 1995). Further, the placement of nursery webs functions as an important indicator of quality Dolomedes habitat since it leads to their reproductive success and survival. Habitats of both species are declining because of anthropic transformation, including draining of wetlands (van Helsdingen, 1993; Hu et al., 2017; Finlayson et al., 2019). Habitats in Fennoscandia are getting more acidic due to forestry practices, resulting in an increase in acidophile plant communities (e.g. Sphagnum, Carex, Blacklocke, 2016, Ellenberg, 1974). While D. fimbriatus is relatively common (Duffey, 2012), D. plantarius is much rarer, and is one of the few red-listed spiders in Europe, despite its fairly broad distribution range (Leroy et al., 2013, 2014). Naturalist observations suggest that $D$. plantarius has more specific habitat requirements than D. fimbriatus (Duffey, 2012). Acidity (low $\mathrm{pH}$ ) has been hypothesized to be a limiting factor for D. plantarius' presence (Duffey, 2012). Habitat loss might have more severe consequences for $D$. plantarius, which has more specific habitat requirements, thus making it a species of conservation interest (Smith, 2000). Investigating the population decline is difficult, because historical distribution data of Dolomedes are scarce (Duffey, 2012). Some authors suggest that there may be denser populations of $D$. plantarius than known, especially in the less monitored areas in eastern Europe (in Belarus: Ivanov, Prishepchik \& Setrakova, 2017). Additionally, misidentifications of the two species were common in the first half of the 20th century, when body color was used for determination, although it is not a reliable indicator for the discrimination of both species (Bonnet, 1930; van Helsdingen, 1993). Little monitoring combined with potential misidentifications and difficult detection of Dolomedes caused an overall lack of knowledge about the distribution and status of the species. Recent observations indicate that co-occurrence, which was considered rare or even impossible, might be more frequent than previously thought (Ivanov, Prishepchik \& Setrakova, 2017).

In this study, we contribute to further characterizing the habitat requirements of the two European Dolomedes species. Based on naturalist observations by van Helsdingen (1993), Duffey (1995), and Duffey (2012), we expect $D$. fimbriatus to be more flexible than $D$. 
94 plantarius in its habitat requirements regarding the presence of water and the specific

95 characteristics of the aquatic habitat.

96

97 Materials \& Methods

98 Study Area and Site Choice

99 In order to find potential Dolomedes habitats, we chose our study sites based on prior

100 observations extracted from the the Global Biodiversity Information Facility (GBIF, 2021) using

101 the R package rgbif (Chamberlain \& Boettiger, 2017) and based on the habitat suitability map of

102 D. plantarius from Leroy et al. (2014). Because the resolution of the suitability map and the

103 accuracy of the GBIF positions were too low for our purpose, we selected sampling areas within

104 the highly suitable habitat and close to the GBIF positions based on information from the

105 literature (van Helsdingen, 1993; Duffey, 1995, 2012). Specifically, we chose water bodies with

106 riparian vegetation and other types of wetlands (bogs, fens, meadows) for data collection.

107 Because the model by Leroy et al. (2014) is only valid for $D$. plantarius, we assessed the

108 potential suitability of additional sites for $D$. fimbriatus based on the visual impression we had of

109 the wetland during a visit (applying similar criteria as for $D$. plantarius, i.e. proximity to water or

110 wet habitat, but somewhat relaxed based on the predictions of $D$. fimbriatus to be less restricted

111 compared to D. plantarius, van Helsdingen, 1993; Duffey, 1995, 2012).The selected locations

112 and the detected species are shown in Fig. 1 and more information on the sites is provided in

113 Table S1.

\section{Data Collection}

115 We developed the data collection protocol by identifying relevant variables from the literature

116 (van Helsdingen, 1993; Duffey, 1995, 2012) followed by a pilot study. We first collected broader

117 habitat variables at the site scale, and then we sampled multiple smaller plots along transects and

118 around the nursery webs to reflect the microhabitat scale. We determined and recorded species of

119 Dolomedes at each site (as part of site scale variables, see below). We delimited each study site

120 by its natural borders, or, for large sites, by five transects covering $40 \mathrm{~m}$ along the water body

121 (Fig. 2). Each site was visited once, and all fieldwork was carried out between the $1^{\text {st }}$ of July

1222018 and the $15^{\text {th }}$ of August 2018. We collected and geo-referenced all data using the data

123 collection software KoBoToolbox (KoBoToolbox, 2020).

\section{Site Scale Data}

125 Since the detectability of free-ranging spiders varies with weather conditions (Noreika et al.,

126 2015), we recorded temperature and wind speed, and visually classified rain and clouds at the

127 beginning of each field work session. In case of wind (Beaufort scale $>3$, equivalent to $12-19$ 
$128 \mathrm{~km} / \mathrm{h}$ wind speed) or rain, we did not attempt to detect the spiders, to keep detection conditions

129 equal.

130 Two of us searched for nursery webs and spiders for 20 minutes before collecting data along

131 transects. The chosen search length was long enough to cover the area, though short enough to

132 prevent disturbing all spiders in the site due to vibration. Further, we detected spiders and

133 nursery webs during the microhabitat data collection on transects, increasing the duration of the

134 effective search. We searched the edge of the vegetation both visually and by sweep-netting

135 while wading through the water if possible. If entering the water was not possible (e.g., due to

136 substrate quality, water depth, or the strength of the current), we moved carefully across the

137 riparian vegetation to the water edge. We mostly found adult females in nursery webs or in

138 nearby vegetation. We captured the spiders in a glass container. If the spider dived, we caught it

139 with a fishing net (mesh size approximately $0.9 \times 0.3 \mathrm{~mm}$ ) from the water and transferred it into

140 a glass container.

141 Once inside the container, we determined the species by pressing the individual gently with a

142 soft sponge against the glass, to inspect the epigyne or pedipalps (a picture of the identification

143 process is available in Supplemental Information 2). We released all spiders after their

144 identification. If we detected only nursery webs but no spider at a site, we discarded the data, as

145 the nursery web of Pisaurida mirabilis cannot safely be distinguished from that of Dolomedes.

146 When we detected and identified Dolomedes in a site, we assumed that all nursery webs were

147 built by Dolomedes, even if we did not actually detect an adult spider near the web. We collected

148 variables regarding vegetation type, land use, and surroundings at the site scale (Table 1). As

149 Dolomedes are semi-aquatic species, measurements on microhabitat scale were concentrated

150 around the water body or in the 'wet center' of study sites without open water, from where we

151 drew transects for further data collection plots.

\section{Microhabitat Data}

153 Within each site, we collected samples at microhabitat scale to relate the specific conditions to

154 the presence of Dolomedes. with the goal to represent the riparian habitat in typical Scandinavian

155 wetlands.

156 We systematically arranged sampling plots along up to five transects (Fig. 2) to collect

157 microhabitat data. If open water was present, we placed the transects perpendicular to the water

158 body and 10 meters apart. If no open water was present, we placed the transects along a wet to

159 dry ground gradient, and if no gradient was detectable, we started the transects from a habitat

160 edge. We recorded the applied sampling procedure for each site.

161 Along each transect, we collected microhabitat scale data in circular plots (radius $=1.5 \mathrm{~m}$ ). Plots

162 were located at two and seven meters from the water edge based on test sites to represent the

163 gradient from aquatic to terrestrial habitat. The focus on the shore-area (or the wettest area in the

164 site) is reflected by the higher density of plots close to the water (Fig. 2). When the riparian

165 vegetation was limited to a few centimeters by the water edge, we included a half-circle $(r=$

$1660.5 \mathrm{~m}$ ) plot with its center at the water edge to represent the vegetation (see Fig. 2). The shape

Peer) reviewing PDF | (2021:08:64722:1:0:NEW 29 Nov 2021) 
167 and size of the additional plot differed from the others to avoid plots overlapping. We collected

168

169

170

171

172

173

174

175

176

177

178

179

180

181

182

183

184

185

186

187

188

189

190

191

192

193

194

195

196

197

198

199

200

201

202

percent cover data for the five most relevant plant species according to literature (Carex spp., Juncus spp., Typha spp., Phragmites spp. and Sphagnum spp.) on the Braun-Blanquet scale (Westhoff \& Van Der Maarel, 1978), which we later simplified for modeling purposes (Table 2). Some of these species, including Carex spp. and Sphagnum spp., thrive in low pH habitats, so this variable also correlates to the microhabitat feature of low $\mathrm{pH}$. Furthermore, we collected structural and microclimate variables (described in Table 3). We collected the same measurements around the nursery webs, which we searched for in the entire site. We extracted site elevation after data collection from a digital elevation model (EEA, 2018).

\section{Statistical Analyses}

We prepared and analyzed all data in R (R Core Team, 2020), and R Studio (RStudio Team, 2012). We followed the protocol for data exploration by Zuur, Ieno \& Elphick (2010) and used the tidyverse framework for data exploration and preparation (Wickham et al., 2019). We standardized all continuous variables to facilitate model convergence and interpretation.

\section{Site Scale Analysis}

In order to investigate differences among occupied habitats, we compared sites in which only $D$. fimbriatus, only $D$. plantarius, both species, or neither species were detected by using flexible discriminant analysis (FDA; Hastie, Tibshirani \& Friedman, 2009, Hastie, Tibshirani \& Buja, 1994) using the R package 'mda' (Hastie et al., 2013). We used the Dolomedes species detection (i.e. D. fimbriatus, D. plantarius, both species, or neither species detected) as the response variable. We considered surrounding landscape and forest type, latitude, elevation, water type, water speed, water clearness, and vegetation type as predictors (Table 1). In addition, we used a single-season occupancy model (MacKenzie et al., 2002) within the unmarked package (Fiske \& Chandler, 2011) to predict the nursery detection probability pooled for both species (because Dolomedes species data are only available at the site scale). We used the microhabitat scale data (collected around nursery webs and along transects) as spatial replicates, as an alternative to the usual temporal replicates/detection attempts. We considered weather, microclimatic variables (wind, cloudiness, rain, shade), vegetation structure, and sampling related variables (see Table 1) as potentially influencing detectability.

\section{Microhabitat Characteristics Around Nursery}

We modeled nursery presence/absence for sites where we verified the presence of Dolomedes and found at least one nursery web. Therefore, we ensured that the sampling was not temporally unsuitable or the site generally unsuitable, which allowed us to model nursery placement within generally suitable sites.

For variable selection and parameter estimation, we fitted a binomial Generalized Additive Model (GAM) by component-wise boosting, using package mboost (function gamboost, Hothorn 
203

204

205

206

207

208

209

210

211

212

213

214

et al., 2020). Prior to model fitting, we checked variables correlation and dropped highly correlated variables (threshold=0.7, Dormann et al., 2013): we retained humidity at ground level and average vegetation height and removed humidity at $20 \mathrm{~cm}$ and maximum vegetation height. We did not consider interactions due to the low sample size. We then fitted a regularized model, following the recommendation in Hofner et al. (2018) using all other predictor variables to identify the most relevant predictors and estimate the model parameters. We validated the model using cross validation and present the final model estimates.

To validate the model, we tested the stability of the selected variables via resampling using the package 'stabs' (Hofner \& Hothorn, 2017). Stability selection provides a reliable way to find an appropriate level of regularization, to keep variables with high selection probabilities. In our model, we used standard choices of tuning parameters, with a cut-off of 0.75 and the number of falsely selected base learners tolerated of 1 (Meinshausen \& Bühlmann, 2010).

\section{Results}

\section{Site Scale Habitat Characteristics - Species Specific}

We detected D. fimbriatus alone in 12 sites, D. plantarius alone in 6 sites, both species together in 4 sites and none of the two species in 9 of the visited sites (total sites: n= 31, Fig. 1). The first axis of the FDA explained $77.3 \%$ of the variation, the second axis $14.1 \%$ of the variation (Fig. 3). The main variables loading onto the FDA axes, i.e., separating best between sites with none/both/each species, were water type and surrounding forest on the first axis, and water speed on the second axis.

Sites holding either of the two species were well separated by the combination of variables loading on the first axis. Sites with only D. plantarius were more restricted with respect to the associated habitat variables, i.e. water type, surrounding forest and water speed as the top loading variables, and sites with both species overlapped mostly with D. plantarius-only sites (Fig. 3, Table 4).

\section{Microhabitat Characteristics Around Nursery}

In the field, we found nurseries in 35 plots out of 184 . The main variables selected in the boosted GAM model (Fig. 4) were distance to water (variable importance $=67.3 \%$ ), Carex spp. cover (variable importance $=11.7 \%)$, crossing structures $($ variable importance $=1.1 \%)$, the random effect site ID (variable importance $=1.3 \%$ ), humidity at ground level (variable importance $=$ $3.6 \%$ ) and the intercept (variable importance $=15.1 \%$ ). We found that high abundances of sedges (Carex spp.), crossing structures, high values of humidity and low distances to water increased the probability of the presence of a Dolomedes nursery (Fig. 5). If water was present, the probability of encountering nursery webs beyond $70 \mathrm{~cm}$ away from the water edge was low. There was variation in the probability of finding nursery webs across sites (Fig. 5). However, 
238

239

240

241

242

243

244

245

246

247

248

249

250

251

252

253

254

255

256

257

258

259

260

261

262

263

264

265

266

267

268

269

270

271

272

273

274

275

when testing the stability of the selected variables via resampling, only distance to water, the intercept and the random site ID were found to be stable enough, which was most likely caused by the small sample size.

The detection probability of nursery webs was higher for plots with a high abundance of crossing structures, higher air temperatures, fewer clouds (at the time of data collection), as well as for sites with open water compared to sites without a water body. Model details can be found in Table S2.

\section{Discussion}

In this study, we found that D. fimbriatus is more of a habitat-generalist than D. plantarius. The habitat requirements of the two species were discriminated by forested habitats, and habitats with low $\mathrm{pH}$ (as indicated by the presence of species such as Carex spp. and Sphagnum spp., Ellenberg, 1974, and the proximity to coniferous forest, Blacklocke, 2016) or absence of water. We frequently found $D$. fimbriatus in forested areas, especially in coniferous forest, while we never encountered $D$. plantarius in these habitats. Duffey (1995) hypothesized that $D$. fimbriatus can occupy habitat with lower $\mathrm{pH}$ values compared to $D$. plantarius. Surrounding coniferous forests, which are dominant in Fennoscandia, may acidify water streams (Blacklocke, 2016), thus impacting the $\mathrm{pH}$ and potentially restricting $D$. plantarius. We found $D$. plantarius most often at sites with slow-flowing rivers, and we found $D$. fimbriatus most often in bogs. D. plantarius was also highly associated with open and slow water, whereas $D$. fimbriatus was less restricted by water conditions. Dolomedes can use water as a hunting area and benefit from the use of vibrations at the water surface to detect prey (Bleckmann \& Lotz, 1987). This close relationship to water, together with the observation of juveniles of $D$. fimbriatus far from the shore, while juveniles of D. plantarius are found on the water (Duffey, 2012), might result from different hunting abilities of the two fishing spider species.

We found some overlap in habitat requirements, which reflected a spatio-temporal overlap at the site scale (see Fig. 3). Holec (2000) hypothesized that co-occurrence of both species might only be observed in transitional habitats between sites suitable for D. plantarius (i.e. ponds) and sites suitable for $D$. fimbriatus (i.e. bogs). This observation is validated for one of the sympatric sites sampled (Fig. 1), a fen in the forest. Nonetheless, we hypothesize that the conditions for cooccurrence are less restrictive because similar to Lecigne (2016), we found two sympatric populations on the vegetation at the shore of a lake (Finjasjön lake, Fig. 1). As already hypothesized by Duffey (2012) and Duffey (1995), and van Helsdingen (1993), our data confirmed the higher degree of association of D. plantarius with water compared to $D$. fimbriatus, and in general more substantial restrictions in potential habitats for the former. This suggests that $D$. plantarius is more specialized in its habitat requirements than $D$. fimbriatus. The co-occurrence of the two species might be explained by a broader ecological niche of $D$. fimbriatus, which partly overlaps with the niche of $D$. plantarius. The co-occurrence observed hide a possible segregation of both fishing spider species at the microhabitat scale. 
276 At the microhabitat scale, D. plantarius might be more dependent on water for its reproductive

277 behavior and nursery placement, which will require further species-specific investigation.

278 Moreover, distance to water and humidity of the ground influenced nursery web placement. This

279 dependency of $D$. plantarius on the water could facilitate cohabitation with $D$. plantarius being

280 spatially segregated towards the shore. We also observed, in two sympatric populations, $D$.

281 plantarius females carrying egg-sac while females of $D$. fimbriatus were already guarding their

282 nursery webs with spiderlings. This might indicate temporal segregation as well, which would

283 also facilitate the co-occurrence of otherwise ecologically close spider species (Uetz, 1977;

284 Fasola \& Mogavero, 1995). Lastly, a segregation for food could occur based on the different diet

285 of the two species, with juveniles of D. plantarius being more restricted to water (Duffey, 2012).

286 Within habitats occupied by Dolomedes, we found at the microhabitat scale that abundance of

287 sedges (Carex sp.) and crossing structures, together with distance to water and humidity, were

288 the most relevant variables for predicting the presence of nursery webs. Indeed, the architecture

289 complexity of the vegetation, as well as the relation between plant community and architecture,

290 are important for wandering spiders (Woodcock et al., 2007; Vasconcellos-Neto et al., 2017).

291 Here, this is expressed by the positive influence of the presence of crossing structures. We also

292 hypothesize that spiders benefit from the stiff stems of the sedge more than being taxonomically

293 exclusive to them for placing nurseries. De Omena \& Romero (2008) showed that some species

294 which are associated with specific host plants are sometimes mostly dependent on the plant's

295 architectural structure for hunting and dwelling. Specifically, prey abundance and resulting prey-

296 predator interactions can depend on vegetation structure (Denno, Finke \& Langellotto, 2005).

297 Thereby, there are multiple possible explanations for the importance of vegetation structure for

298 Dolomedes.

299 In this study, our sample size was small due to the rarity of the two species, especially of $D$.

300 plantarius, and to a narrow temporal window for data collection. At the site scale, this small

301 sample, and especially the lack of co-occurrence sites limits the scope of our conclusions about

302 the characteristics of sympatric populations. At the microhabitat scale, repeated visits of the

303 same sites would provide opportunities to refine the occupancy model and to clarify detection

304 issues for these two species. With a better knowledge of nursery timing, other microhabitat

305 studies would also be facilitated. Further data collection at the landscape level would increase

306 knowledge about potential habitat, and investigating water and soil acidity could be helpful to

307 clarify habitat restrictions for $D$. plantarius. Finally, species-specific occupancy modeling could

308 be helpful, especially because $D$. plantarius is likely to dive when disturbed and might be more

309 difficult to detect than $D$. fimbriatus, which might prevent identification of double-species sites.

310 The habitat suitability for both species is expected to shift northward in Europe in response to

311 climate change (Leroy et al., 2013, 2014; Monsimet et al., 2020). This shift might be limited by

312 low dispersal abilities and unconnected habitats in Fennoscandia (Monsimet et al., 2020). The

313 lower dispersal abilities of D. plantarius (J Monsimet, 2021, unpublished data), combined with

314 its narrower habitat requirements may explain its more restricted distribution and scarcer

315 populations. It is therefore essential to protect both current and future habitats. Conserving both 
316 Dolomedes species emphasizes the special importance of protecting wetlands, in Fennoscandia

317 and elsewhere (Sala et al., 2000; Davidson, 2014; Carson et al., 2019). The conservation of the

318 red-listed D. plantarius might be prioritized as it seems to have narrower habitat requirements

319 than D. fimbriatus, which makes it more vulnerable to climate change (Cardoso et al., 2020).

320 To counteract various threats, which spiders currently face, land protection and the management

321 of both land and species, is important (Branco \& Cardoso, 2020). For efficient management,

322 estimating the local probability of presence of the species is also important. Occupancy modeling

323 can help to decide which areas could be necessary to protect and where to apply conservation

324 efforts (McFarland et al., 2012). In this study, the detection probability of nursery webs was

325 higher where abundance of crossing vegetation structures was high and with good weather

326 condition, i.e., optimal temperature and sunny weather. Nonetheless, the use of nursery webs as

327 detection units could be improved by specifying the timing and duration of nursery webs with

328 repeated visits (e.g. weekly) to the same sites and nursery webs (Smith, 2000). Monitoring

329 nursery webs also makes it possible to encounter the female spiders, which is especially valuable

330 with the non-invasive sponge-technique we used for identifying the species. Furthermore, spatial

331 patterns between adults and webs of the same and different species of Dolomedes could give

332 further insight into co-occurrence as well as abundance. Spatial patterns, beside habitat

333 characteristics, could potentially arise due to positive (e.g. finding a mate) or negative

334 interactions (e.g. cannibalism, predation) between individuals of the same or different

335 Dolomedes species or just due to the lack of dispersal of individuals. In addition to estimating the

336 population's abundance dynamics, preserving shorelines with abundant crossing structures and

337 continuously web habitats are essential to managing and conserving populations of $D$. plantarius.

338

339

\section{Conclusions}

340 In this study, we found that $D$. fimbriatus is more of a habitat-generalist than $D$. plantarius. The

341 former can occupy sites with a lower $\mathrm{pH}$, indicated here by the presence of characteristic

342 vegetation and the proximity to coniferous forest. $D$. plantarius is also less tolerant to the

343 absence of water. Moreover, we found some overlap in their habitat, with the overlap site more

344 similar to D. plantarius sites.

345 Abundance of sedges, crossing structures, distance to water and ground humidity influence the presence of nursery webs. The information at the site and the microhabitat scales provides relevant information for the management of both species.

350

351

We thank Lars Jonsson (Kristianstad University) for his advice and help during the data

352 collection, Andres Ordiz for comments on a previous manuscript version, and Boris Leroy for sharing with us his prediction maps to select sites.

353 We would like to thank Marc Milne and two anonymous referees who provided useful and 354 detailed comments on the manuscript. 
356 References

357 Blacklocke S. 2016. Progressing understanding of episodic stream acidification in upland

358 plantation conifer forested subcatchments in Ireland. Ireland: University College Dublin. School

359 of Civil Engineering.

360 Bleckmann H, Lotz T. 1987. The vertebrate-catching behaviour of the fishing spider Dolomedes

361 triton (Araneae, Pisauridae). Animal Behaviour 35:641-651. DOI: ckgwj5.

362 Bonnet P. 1930. La mue, l'autotomie et la régénération chez les Araignées, avec une étude des

363 Dolomèdes d'Europe. Bulletin de la société d'histoire naturelle de Toulouse 59:237-700.

364 Branco VV, Cardoso P. 2020. An expert-based assessment of global threats and conservation

365 measures for spiders. Global Ecology and Conservation 24:e01290. DOI: gh433s.

366 Cardoso P, Barton PS, Birkhofer K, Chichorro F, Deacon C, Fartmann T, Fukushima CS,

367 Gaigher R, Habel JC, Hallmann CA, Hill MJ, Hochkirch A, Kwak ML, Mammola S, Ari

368 Noriega J, Orfinger AB, Pedraza F, Pryke JS, Roque FO, Settele J, Simaika JP, Stork NE,

369 Suhling F, Vorster C, Samways MJ. 2020. Scientists' warning to humanity on insect extinctions.

370 Biological Conservation 242:108426. DOI: ggk8q7.

371 Carson M, Kibria G, Löfroth M, Macura B, Alm DS, Kalantari Z. 2019. Arctic wetlands: Time

372 bomb or saving grace? SEI Project Brief:1-4.

373 Chamberlain S, Boettiger C. 2017. R Python, and Ruby clients for GBIF species occurrence data.

374 PeerJ PrePrints e3304v1.

375 Clark JA, May RM. 2002. Taxonomic bias in conservation research. Science 297:191-192. DOI:

376 bdfph6.

377 Darwall WRT, Holland RA, Smith KG, Allen D, Brooks EGE, Katarya V, Pollock CM, Shi Y,

378 Clausnitzer V, Cumberlidge N, Cuttelod A, Dijkstra KDB, Diop MD, Garcia N, Seddon MB,

379 Skelton PH, Snoeks J, Tweddle D, Vié JC. 2011. Implications of bias in conservation research

380 and investment for freshwater species. Conservation Letters 4:474-482. DOI: dfhtsd.

381 Davidson NC. 2014. How much wetland has the world lost? Long-term and recent trends in

382 global wetland area. Marine and Freshwater Research 65:934-941. DOI: f6n53b.

383 De Groot R, Stuip M, Finlayson M, Davidson NC. 2006. Valuing wetlands. Guidance for valuing

384 the benefits derived from wetland ecosystem services. Gland, Switzerland: International Water

385 Management Institute.

386 Denno RF, Finke DL and Langellotto GA. 2005. Direct and indirect effects of vegetation

387 structure and habitat complexity on predator-prey and predator-predator interactions. In: Ecology

388 of predator-prey interactions, Oxford University Press, 211-239.

389 De Omena PM, Romero GQ. 2008. Fine-scale microhabitat selection in a bromeliad-dwelling

390 jumping spider (Salticidae). Biological Journal of the Linnean Society 94:653-662. DOI: bk5bt8.

391 Dormann CF, Elith J, Bacher S, Buchmann C, Carl G, Carré G, Marquéz J, Gruber B,

392 Lafourcade B, Leitao P, Münkemüller T, McClean C, Osborne P, Reineking B, Schröder B,

393 Skidmore AK, Zurell D, Lautenbach S. 2013. Collinearity: A review of methods to deal with it

394 and a simulation study evaluating their performance. Ecography 36:27-46. DOI: $\underline{\mathrm{f} 4 \mathrm{scb} 2}$. 
395 Duffey E. 1995. The distribution, status and habitat of Dolomedes fimbriatus (Clerck) and $D$.

396 plantarius (Clerck) in Europe. Proceedings of the 15th European Colloquium of

397 Arachnology:54-65.

398 Duffey E. 2012. Dolomedes plantarius (Clerck, 1757) (Araneae: Pisauridae): A reassessment of

399 its ecology and distribution in Europe, with comments on its history at Redgrave and Lopham

400 Fen, England. Bulletin of the British Arachnological Society 15:285-292.

401 EEA. 2018. European Union, Copernicus Land Monitoring Service 2018, European Environment

402 Agency (EEA).

403 Ellenberg H. 1974. Zeigerwerte der Gefässpflanzen Mitteleuropas. Scripta geobotanica.

404 Göttingen 9:197 p.

405 Fasola M, Mogavero F. 1995. Structure and habitat use in a web-building spider community in

406 northern Italy. Bollettino di zoologia 62:159-166. DOI: dnmds5.

407 Finlayson CM, Davies GT, Moomaw WR, Chmura GL, Natali SM, Perry JE, Roulet N, Sutton-

408 Grier AE. 2019. The second warning to humanity - providing a context for wetland management

409 and policy. Wetlands 39:1-5. DOI: gh4337.

410 Fiske IJ, Chandler RB. 2011. Unmarked: An R package for fitting hierarchical models of wildlife

411 occurrence and abundance. Journal of Statistical Software 43:1-23. DOI: gfkktx.

412 GBIF: The Global Biodiversity Information Facility. 2021. What is GBIF? Available at

413 https://www.gbif.org/what-is-gbif

414 Gorb SN, Barth FG. 1994. Locomotor behavior during prey-capture of a Fishing Spider,

415 Dolomedes plantarius (Araneae: Araneidae): Galloping and stopping. Journal of Arachnology

416 22:89-93.

417 Hastie T, Tibshirani R, Buja A. 1994. Flexible discriminant analysis by optimal scoring. Journal

418 of the American Statistical Association 89:1255-1270. DOI: gf56fz.

419 Hastie T, Tibshirani R, Friedman J. 2009. The elements of statistical learning: data mining,

420 inference, and prediction. Second Edition, Springer Verlag.

421 Hastie T, Tibshirani R, Leisch F, Hornik K, Ripley B. 2013. Mda: Mixture and flexible

422 discriminant analysis. $R$ package version 0.4-4, URL http://cran. $r$-project. org/package $=m d a$.

423 Hofner B, Hothorn T. 2017. Stabs: Stability selection with error control (2017). URL

424 https://CRAN. R-project. org/package = stabs. $R$ package version 0.6-3.

425 Hofner B, Mayr A, Fenske N, Thomas J, Schmid M. 2018. gamboostLSS: Boosting methods for

426 GAMLSS models. URL http://CRAN. R-project. org/package= gamboostLSS. R package

427 version:2.0-1.1.

428 Holec M. 2000. Spiders (Araneae) of the fishpond eulittoral zone. Ekológica (Bratislava) 19:5142954.

430 Hothorn T, Buehlmann P, Kneib T, Schmid M, Hofner B. 2020. mboost: Model-based boosting. 431 Hu S, Niu Z, Chen Y, Li L, Zhang H. 2017. Global wetlands: Potential distribution, wetland loss, 432 and status. Science of the Total Environment 586:319-327. DOI: gfv39s. 
433 Ivanov V, Prishepchik O, Setrakova E. 2017. Dolomedes plantarius (Araneae, Pisauridae) in 434 Belarus: Records, distribution and implications for conservation. Arachnologische Mitteilungen 435 54:33-37. DOI: gh434m.

436 Kellner KF, Swihart RK. 2014. Accounting for imperfect detection in ecology: A quantitative 437 review. PloS ONE 9:e111436. DOI: gd882s.

438 Kendall HW. 1992.World Scientists' Warning to Humanity. Available at

439 https://www.ucsusa.org/resources/1992-world-scientists-warning-humanity (accessed October 7, 440 2020).

441 KoBoToolbox. 2020.http://www.kobotoolbox.org

442 Lecigne S. 2016. Redécouverte de Dolomedes plantarius (Clerck, 1758)(Araneae, Pisauridae) en 443 région Nord-Pas-de-Calais (France), actualisation de sa distribution en France et aperçu de la 444 situation en Europe. Revue arachnologique 2:28-41.

445 Leroy B, Bellard C, Dubos N, Colliot A, Vasseur M, Courtial C, Bakkenes M, Canard A, Ysnel 446 F. 2014. Forecasted climate and land use changes, and protected areas: The contrasting case of 447 spiders. Diversity and Distributions 20:686-697. DOI: f5zrhr.

448 Leroy B, Paschetta M, Canard A, Bakkenes M, Isaia M, Ysnel F. 2013. First assessment of 449 effects of global change on threatened spiders: Potential impacts on Dolomedes plantarius 450 (Clerck) and its conservation plans. Biological Conservation 161:155-163. DOI: gh434t.

451 Lindenmayer D, Hunter M. 2010. Some guiding concepts for conservation biology.

452 Conservation Biology 24:1459-1468. DOI: c76w3t.

453 MacKenzie DI, Nichols JD, Lachmann S, Droege J, Royle JA, Langtimm CA. 2002. Estimating 454 site occupancy rates when detection probabilities are less than one. Ecology 83:2248-2255. DOI: 455 fwj6vt.

456 McFarland TM, Mathewson HA, Groce JE, Morrison ML, Newnam JC, Snelgrove RT, Skow

457 KL, Collier BA, Wilkins RN. 2012. Utilization of a species occupancy model for management 458 and conservation. Wildlife Society Bulletin 36:432-439. DOI: fzxbk8.

459 Meinshausen N, Bühlmann P. 2010. Stability selection. Journal of the Royal Statistical Society:

460 Series $B$ (Statistical Methodology) 72:417-473. DOI: cqs5hw.

461 Monsimet J, Devineau O, Pétillon J, Lafage D. 2020. Explicit integration of dispersal-related

462 metrics improves predictions of SDM in predatory arthropods. Scientific Reports 10:1-12. DOI: 463 gh4345.

464 Noreika N, Kotiaho JS, Penttinen J, Punttila P, Vuori A, Pajunen T, Autio O, Joukola OJ, Kotze 465 DJ. 2015. Rapid recovery of invertebrate communities after ecological restoration of boreal 466 mires. Restoration Ecology 23:566-579. DOI: $\underline{\mathrm{f} 7 \mathrm{wvj} 7 .}$

467 R Core Team. 2020. R: A language and environment for statistical computing. Vienna, Austria:

468 R Foundation for Statistical Computing.

469 Ramsar. 2013. The Ramsar convention manual: A guide to the convention on wetlands (Ramsar, 470 iran, 1971). Gland, Switzerland: Ramsar Convention Bureau; Ramsar Convention Secretariat.

471 Roberts MJ. 1995. Collins Field Guide - Spiders of Britain \& Northern Europe. London:

472 HarperCollins Publishers. 
473 RStudio Team. 2012. RStudio: Integrated development environment for R.

474 Sala OE, Chapin FS, Armesto JJ, Berlow E, Bloomfield J, Dirzo R, Hubner-Sanwald E,

475 Huenneke LF, Jackson RB, Kinzig A, Leemans R, M.Lodge D, Mooney HA, Oesterheld M, Poff

476 NL, Sykes MT, Walker BH, Hall DW. 2000. Global biodiversity scenarios for the year 2100.

477 Science 287:1770-1774. DOI: cdhbzm.

478 Smith H. 2000. The status and conservation of the fen raft spider (Dolomedes plantarius) at

479 Redgrave and Lopham fen national nature reserve, England. Biological Conservation 95:153-

480 164. DOI: ddpptx.

481 Stratton GE, Suter RB, Miller PR. 2004. Evolution of water surface locomotion by spiders: A

482 comparative approach. Biological Journal of the Linnean Society 81:63-78. DOI: $\mathrm{dm} 4 \mathrm{f2c}$.

483 Uetz GW. 1977. Coexistence in a guild of wandering spiders. Journal of Animal Ecology

484 46:531-541. DOI: fb89p3.

485 van Helsdingen PJ. 1993. Ecology and distribution of Dolomedes in Europe (Araneida:

486 Dolomedidae). Bolletino dell'Accademia Gioenia di Scienze Naturali 26:181-187.

487 Vasconcellos-Neto J, Messas YF, da Silva Souza H, Villanueva-Bonila GA, Romero GQ. 2017.

488 Spider-plant interactions: An ecological approach. In: Behaviour and ecology of spiders.

489 Springer, 165-214.

490 Westhoff V, Van Der Maarel E. 1978. The braun-blanquet approach. In: Classification of plant 491 communities. Springer, 287-399.

492 Wickham H, Averick M, Bryan J, Chang W, McGowan LD, François R, Grolemund G, Hayes

493 A, Henry L, Hester J, Kuhn M, Pedersen TL, Miller E, Bache SM, Müller K, Ooms J, Robinson

494 D, Seidel DP, Spinu V, Takahashi K, Vaughan D, Wilke C, Woo K, Yutani H. 2019. Welcome

495 to the tidyverse. Journal of Open Source Software 4:1686. DOI: ggddkj.

496 Woodcock BA, Potts SG, Westbury DB, Ramsay AJ, Lambert M, Harris SJ, Brown VK. 2007.

497 The importance of sward architectural complexity in structuring predatory and phytophagous

498 invertebrate assemblages. Ecological Entomology 32:302-311. DOI: bfhv2r.

499 Zuur AF, Ieno EN, Elphick CS. 2010. A protocol for data exploration to avoid common

500 statistical problems. Methods in Ecology and Evolution 1:3-14. DOI: cw57t3.

501

\section{Data availability}

503 We added new records to artsobservasjoner and artportalen.

504 Dataset and code are available on gitlab. 
Figure 1

Overview map of the study area in Sweden and Norway (left) with detailed maps of the three study areas (right).

Dots represents the study sites (Pink: both species; red: $D$. plantarius; light blue: $D$.

fimbriatus; dark blue: absence sites; light green: Dolomedes sp.). Finjasjön lake:

southernmost pink dot in the bottom right map. The background map is obtained from

OpenStreetMap.

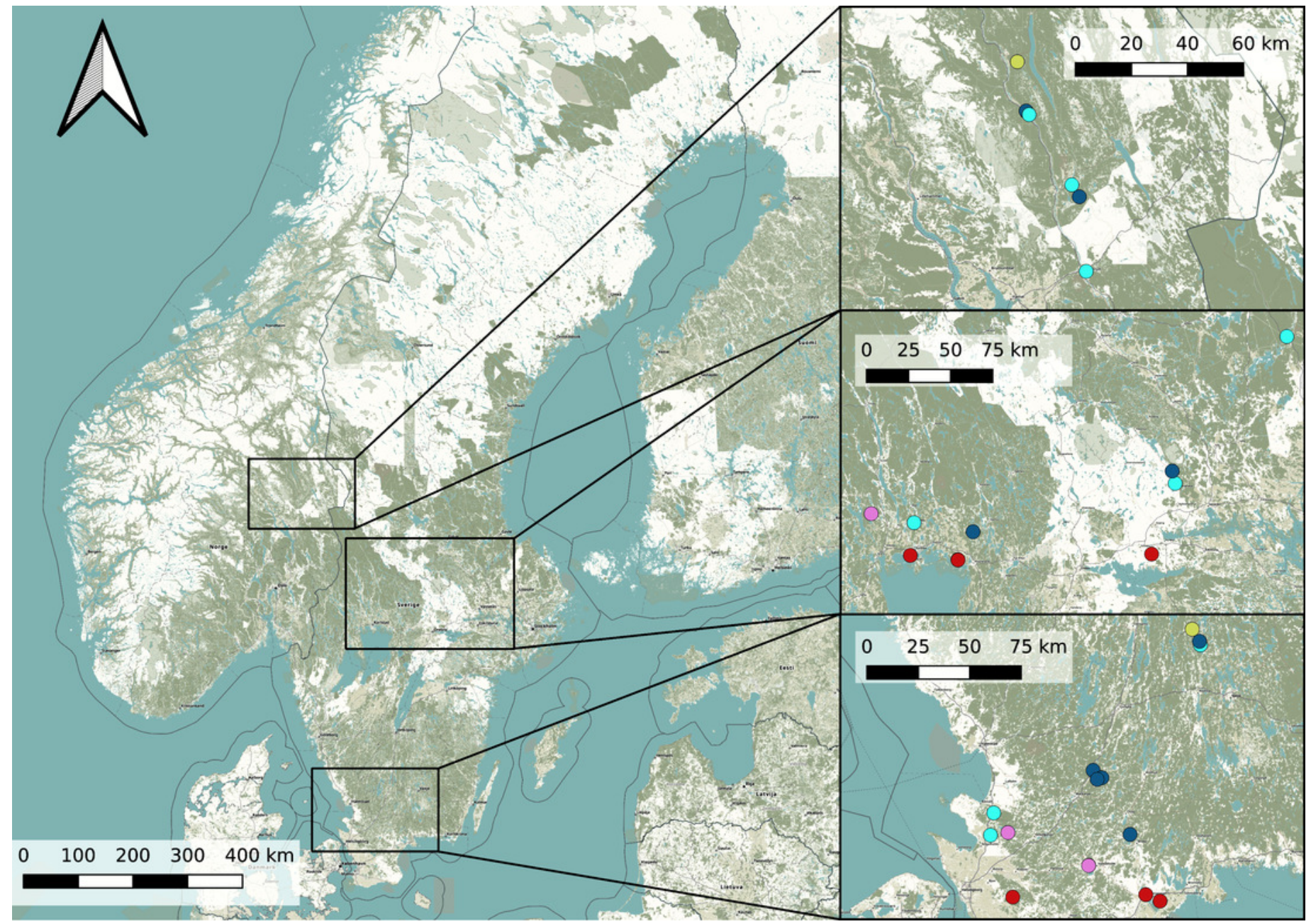




\section{Figure 2}

Arrangement of plots and transects.

Distance between transects was $10 \mathrm{~m}$, and we measured maximum 5 transects $(=40 \mathrm{~m})$.

Microhabitat variables and nursery presence were collected within the terrestrial plots. If the riparian vegetation or wet vegetation area was broad, data were collected as in the transect shown on the left hand. If the stripe of riparian vegetation was narrow, we inserted a halfcircle directly at the water edge, as shown on the right-hand side (transect on the right).

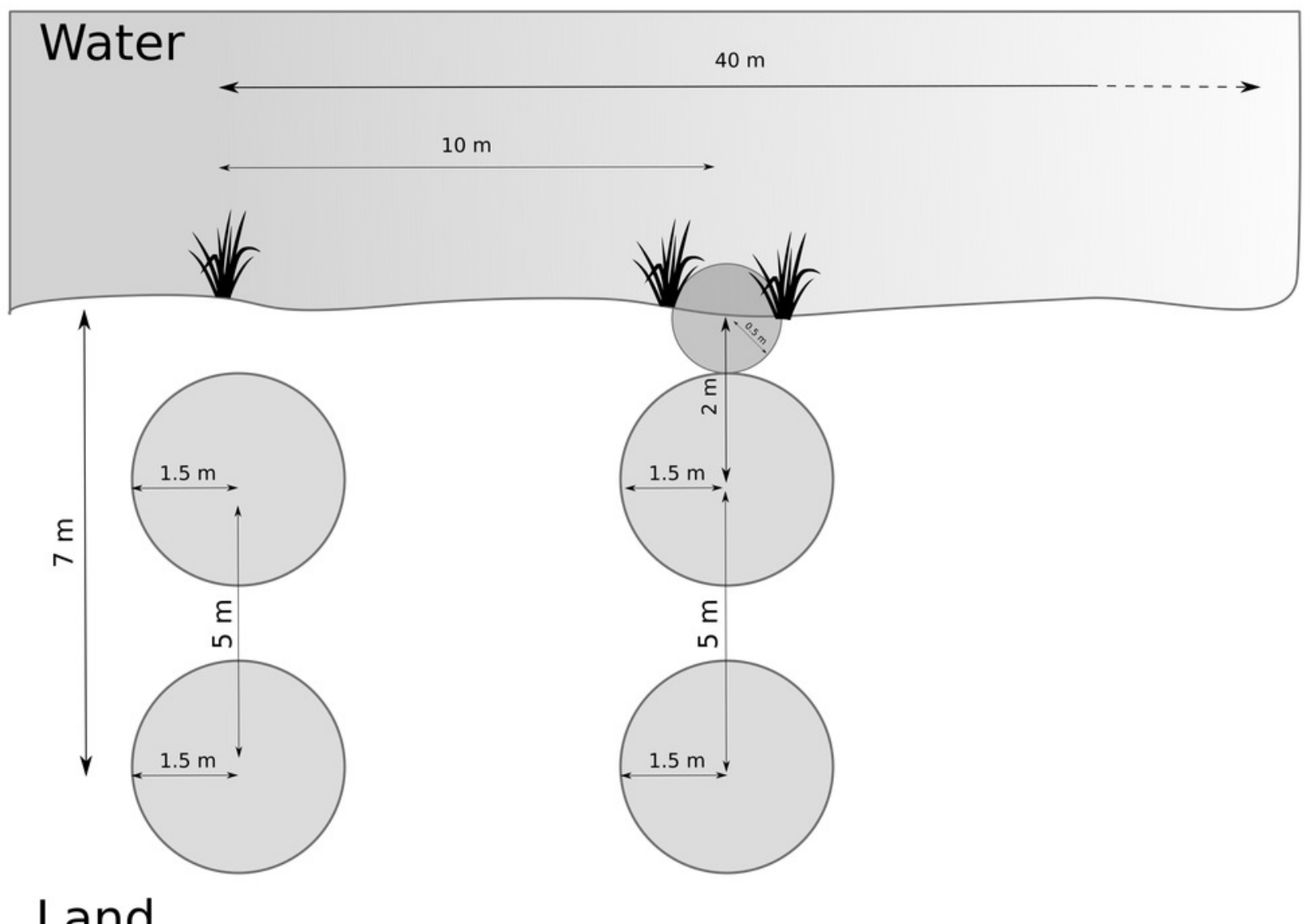




\section{Figure 3}

Plot of the results from the flexible discriminant analysis (FDA), where colors represent observed occurrences of the species, shapes predicted occurrences, and ellipses indicate uncertainty of predicted species occurrences ( $95 \%$ confidence intervals).

Presence of both species (observed: red, actual: circle), only D. fimbriatus (observed: green, actual: triangle), only D. plantarius(observed: purple, actual: cross) and no Dolomedes (observed: black, actual: square). 


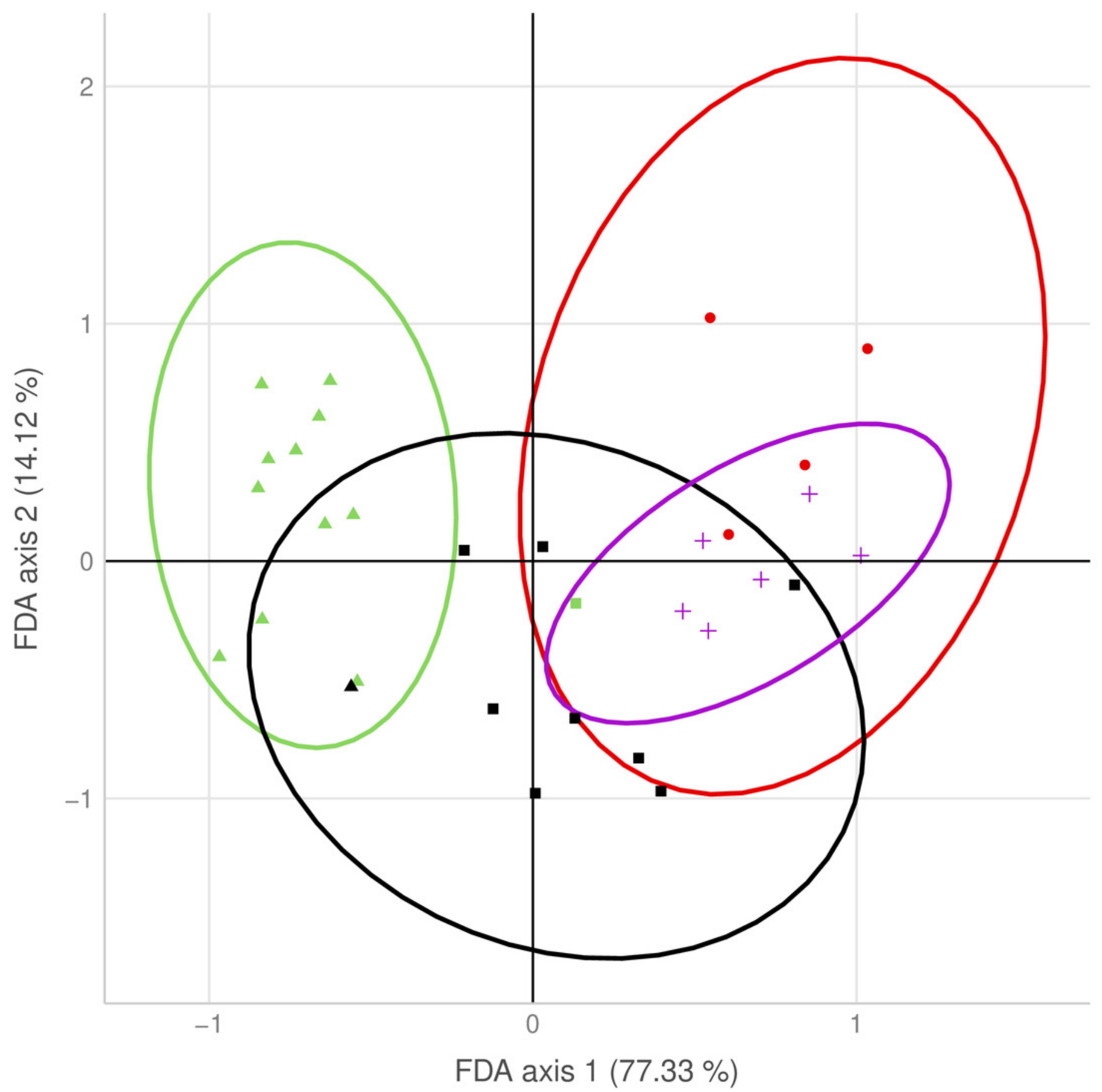




\section{Figure 4}

Variables importance for the nursery placement model (boosted GAM).

The "intercept" variable is the combination of the first level of each factor at humidity $=0$.

Distance water: distance to water, Sedges: abundance of Carex spp. on simplified Braun-

Blanquet scale, Crossing structure: crossing vegetation structures on simplified Braun-

Blanquet-scale, Site ID: varying intercept per site ID, Humidity ground: humidity at ground level (standardized). 


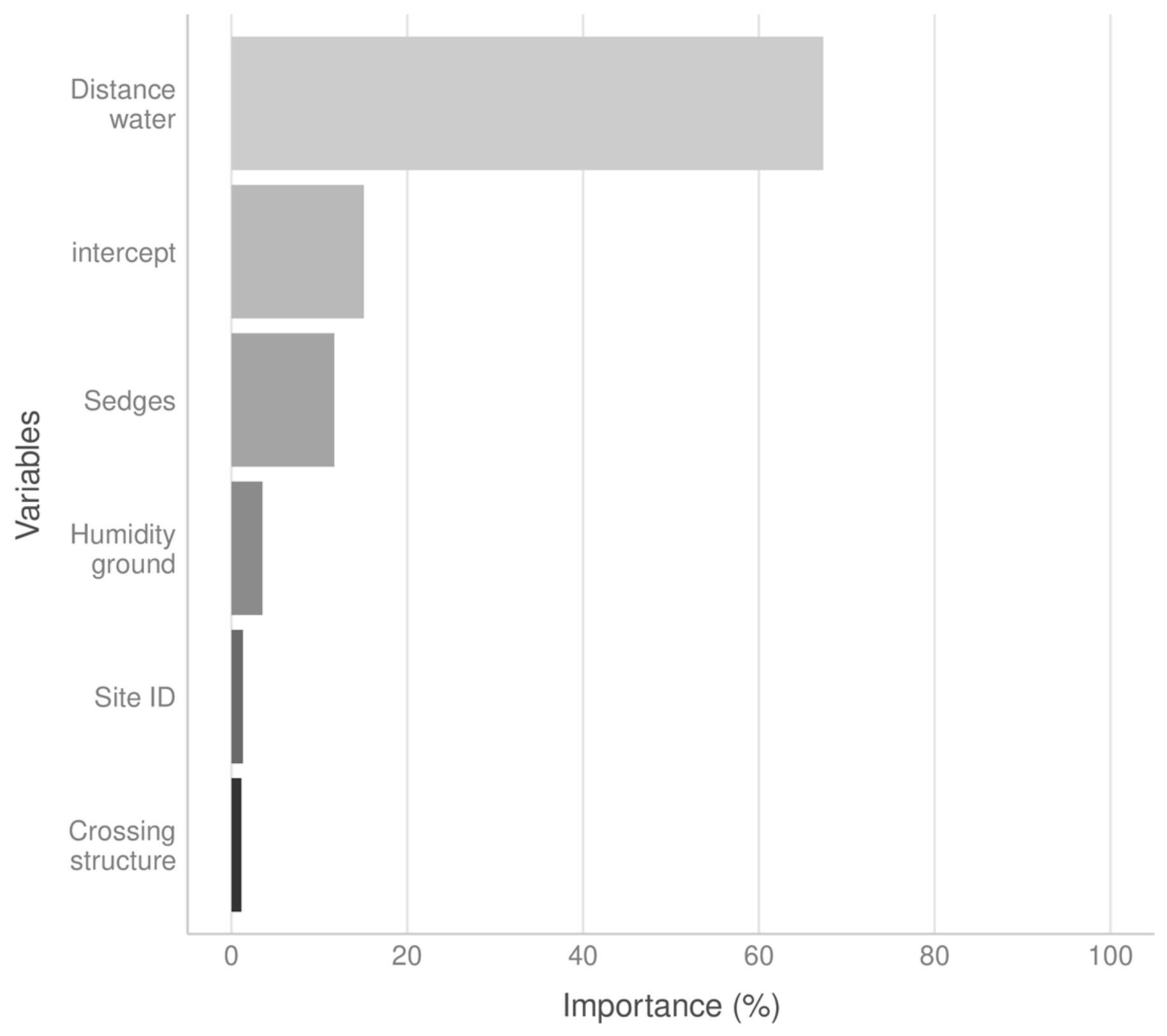




\section{Figure 5}

Marginal effects of variables selected in the nursery placement model (boosted GAM).

Value above/below zero represents a positive/negative effect, with the further the value is from the red line, the greater is the effect. (A) Impact of the distance to water (categorical variable, category 0 meter in the intercept), (B) of the abundance of sedges (categorical variable, intercept: 0 ), (C) of the abundance of crossing vegetation structures (categorical variable, intercept: 0 ) and (D) of the ground humidity (continuous variable) on the presence of nursery. (E) The effect of sites (categorical variable), considered as random effect. 

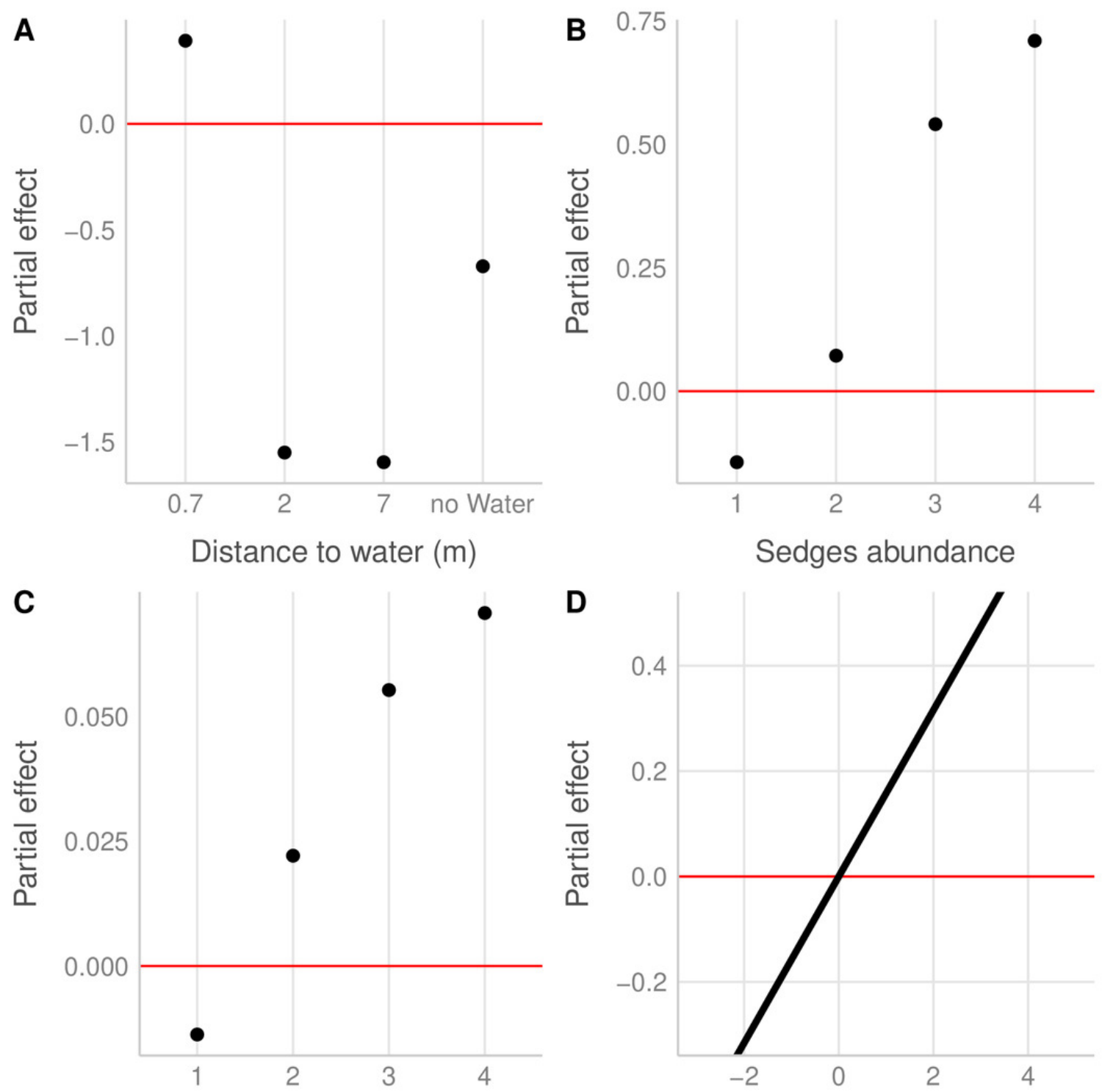

Crossing structures abundance

Scaled ground humidity

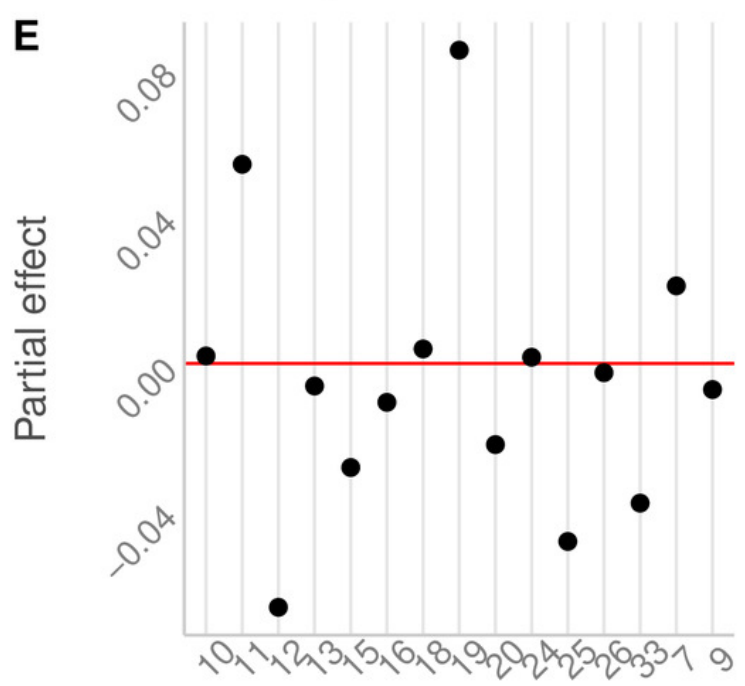

Site ID (random effect) 


\section{Table 1 (on next page)}

Levels and explanations of variables on site scale. 


\begin{tabular}{ll}
\hline Variable & Levels \\
\hline Surrounding & Infrastructure/forest/other \\
Surrounding forest & Deciduous/coniferous/mixed \\
Water type & River/bog/lake/creek \\
Water speed & Standing/slow/fast \\
Water clearness & Clear/brown/murky \\
Vegetation type (at site) & Open wet/open dry/deciduous forest/coniferous forest \\
Latitude & Latitude (continuous), Digital Elevation Model (DEM) \\
Elevation & Elevation (continuous), DEM \\
Clouds (detectability) & Yes/no/partly \\
Wind (detectability) & Measured with anemometer on Beaufort scale \\
Reason visit & Suitable habitat/GBIF/other \\
\hline
\end{tabular}

1 


\section{Table 2 (on next page)}

Braun Blanquet scale and simplification used in this study.

The Braun Blanquet scale combines both cover and abundance (Percentage plant coverage and Number of occurrences). The simplified categories were used to reduce the degree of freedom of our models (Table adapted from Westhoff and Van Der Maarel, 1978). 


\begin{tabular}{llll}
\hline $\begin{array}{l}\text { Percentage } \\
\text { plant } \\
\text { coverage }\end{array}$ & Number of occurrences & Original Braun Blanquet category & Simplified category \\
\hline 0 & 0 & no & \\
$<5$ & 1 & r & 0 \\
$<5$ & $2-5$ & + & 1 \\
\hline$<5$ & Abundant & 1 & 2 \\
$5-25$ & Very abundant & 2 & 3 \\
\hline $26-50$ & Arbitrary & 3 & 4 \\
\hline $51-75$ & Arbitrary & 4 & \\
\hline $76-100$ & Arbitrary & 5 & \\
\hline 1
\end{tabular}




\section{Table 3(on next page)}

Levels and explanations of variables on microhabitat scale.

BB: Braun Blanquet. 


Variable Levels

Spiders detection

Distance to water

Humidity

Horizontal cover

Maximum height

Average height

Tussocs

Large leaves

Litter

Shade

Crossing structures

Carex spp.

Juncus spp.

Typha spp.

Phragmites spp.

Sphagnum spp.

Deciduous plants

Aquatic vegetation

Nursery web detected
Spider/nursery web/no

No water; $0 \mathrm{~m} ; 0.7 \mathrm{~m} ; 2 \mathrm{~m} ; 7 \mathrm{~m}$

Measured at ground level and $20 \mathrm{~cm}$ above ground

Visually assessed at $10 \mathrm{~cm} ; 30 \mathrm{~cm} ; 50 \mathrm{~cm}$ above ground, indicating the proportion of the area covered by vegetation

Maximal height of vegetation in plot, measured with $10 \mathrm{~cm}$ accuracy

Measured 5 times in random location within plot with $10 \mathrm{~cm}$ accuracy

Tuft of grasses or sedges, measured on BB scale

Yes/no; this variable indicates green plant parts which are deciduous or broad (opposed to stems or grass shaped leaves)

Yes/no

Yes/no/partly

When stems or leaves cross to form a "platform", measured on BB scale

Cover-abundance measured on BB scale

Cover-abundance measured on BB scale

Cover-abundance measured on BB scale

Cover-abundance measured on BB scale

Cover-abundance measured on BB scale

Cover-abundance measured on BB scale

Yes/no

Yes/no 


\section{Table 4 (on next page)}

Loading values of the variables in the three axes of the FDA (flexible discriminant analysis). 


\begin{tabular}{|c|c|c|c|c|}
\hline Variable & Category & Axis 1 & Axis 2 & Axis 3 \\
\hline Elevation & & -0.3 & -0.4 & -0.54 \\
\hline \multirow[t]{4}{*}{ Latitude } & & -0.22 & 0.22 & -0.13 \\
\hline & Pine deciduous & -0.27 & -0.32 & -0.21 \\
\hline & Other & -0.27 & 0.26 & 0.57 \\
\hline & Pine & -0.23 & 0.24 & 0.06 \\
\hline \multirow[t]{6}{*}{$\begin{array}{l}\text { Surrounding and } \\
\text { forest }\end{array}$} & Deciduous & -0.1 & 0.37 & -0.69 \\
\hline & Spruce & 0.02 & -0.46 & 0.08 \\
\hline & Infrastructure & 0.09 & -0.13 & -0.12 \\
\hline & Fields & 0.77 & 0.04 & 0.32 \\
\hline & Open dry & -0.69 & -0.06 & -0.15 \\
\hline & Open wet & -0.04 & 0.2 & -0.22 \\
\hline \multirow{3}{*}{ Vegetation type } & Coniferous & 0.34 & 0.09 & -0.03 \\
\hline & Deciduous & 0.37 & 0.23 & 0.32 \\
\hline & Clear & -0.15 & -0.38 & 0.5 \\
\hline \multirow[t]{3}{*}{ Water clearness } & No water & -0.05 & 0.17 & -0.15 \\
\hline & Murky & -0.04 & -0.76 & -0.03 \\
\hline & No water & -0.05 & 0.17 & -0.15 \\
\hline \multirow[t]{4}{*}{ Water speed } & Slow & 0.04 & -0.07 & 0.51 \\
\hline & Standing & 0.47 & -0.01 & -0.14 \\
\hline & Other & 0.16 & 0.02 & -0.17 \\
\hline & Creek & 0.29 & 0.56 & -0.61 \\
\hline \multirow{2}{*}{ Water type } & Lake & 0.39 & -0.02 & 0.18 \\
\hline & River & 0.55 & -0.51 & -0.27 \\
\hline
\end{tabular}

